\title{
Near-infrared spectroscopy after out-of-hospital cardiac arrest
}

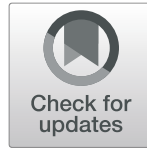

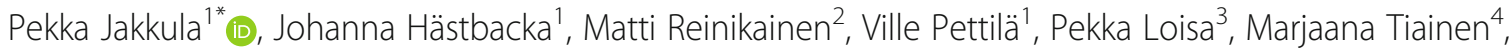
Erika Wilkman', Stepani Bendel ${ }^{5}$, Thomas Birkelund ${ }^{6}$, Anni Pulkkinen$^{7}$, Minna Bäcklund', Sirkku Heino ${ }^{8}$, Sari Karlsson ${ }^{9}$, Hiski Kopponen ${ }^{1}$ and Markus B. Skrifvars ${ }^{10}$

\begin{abstract}
Background: Cerebral hypoperfusion may aggravate neurological damage after cardiac arrest. Near-infrared spectroscopy (NIRS) provides information on cerebral oxygenation but its relevance during post-resuscitation care is undefined. We investigated whether cerebral oxygen saturation $\left(\mathrm{rSO}_{2}\right)$ measured with NIRS correlates with the serum concentration of neuron-specific enolase (NSE), a marker of neurological injury, and with clinical outcome in out-of-hospital cardiac arrest (OHCA) patients.
\end{abstract}

Methods: We performed a post hoc analysis of a randomised clinical trial (COMACARE, NCT02698917) comparing two different levels of carbon dioxide, oxygen and arterial pressure after resuscitation from OHCA with ventricular fibrillation as the initial rhythm. We measured $\mathrm{rSO}_{2}$ in 118 OHCA patients with NIRS during the first $36 \mathrm{~h}$ of intensive care. We determined the NSE concentrations from serum samples at $48 \mathrm{~h}$ after cardiac arrest and assessed neurological outcome with the Cerebral Performance Category (CPC) scale at 6 months. We evaluated the association between $\mathrm{rSO}_{2}$ and serum NSE concentrations and the association between $\mathrm{rSO}_{2}$ and good (CPC 1-2) and poor (CPC 3-5) neurological outcome.

Results: The median (inter-quartile range (IQR)) NSE concentration at $48 \mathrm{~h}$ was $17.5(13.4-25.0) \mu \mathrm{g} / \mathrm{l}$ in patients with good neurological outcome and $35.2(22.6-95.8) \mu \mathrm{g} / \mathrm{l}$ in those with poor outcome, $p<0.001$. We found no significant correlation between median $\mathrm{rSO}_{2}$ and NSE at $48 \mathrm{~h}, r_{s}=-0.08, p=0.392$. The median (IQR) $\mathrm{rSO}_{2}$ during the first $36 \mathrm{~h}$ of intensive care was 70.0\% (63.5-77.0\%) in patients with good outcome and 71.8\% (63.3-74.0\%) in patients with poor outcome, $p=0.943$. There was no significant association between $\mathrm{rSO}_{2}$ over time and neurological outcome. In a binary logistic regression model, $\mathrm{rSO}_{2}$ was not a statistically significant predictor of good neurological outcome (odds ratio 0.99, 95\% confidence interval $0.94-1.04, p=0.635$ ).

Conclusions: We found no association between cerebral oxygenation measured with NIRS and NSE concentrations or outcome in patients resuscitated from OHCA.

Trial registration: ClinicalTrials.gov, NCT02698917. Registered on 26 January 2016.

Keywords: Cardiac arrest, Cerebral oxygenation, Hypoxic ischemic encephalopathy, Intensive care, Neuron-specific enolase (NSE)

\footnotetext{
* Correspondence: pekka.jakkula@me.com

'Department of Anaesthesiology, Intensive Care and Pain Medicine,

University of Helsinki and Helsinki University Hospital, Helsinki, Finland

Full list of author information is available at the end of the article
}

(c) The Author(s). 2019 Open Access This article is distributed under the terms of the Creative Commons Attribution 4.0 International License (http://creativecommons.org/licenses/by/4.0/), which permits unrestricted use, distribution, and reproduction in any medium, provided you give appropriate credit to the original author(s) and the source, provide a link to the Creative Commons license, and indicate if changes were made. The Creative Commons Public Domain Dedication waiver (http://creativecommons.org/publicdomain/zero/1.0/) applies to the data made available in this article, unless otherwise stated. 


\section{Background}

Cerebral hypoperfusion may lead to diminished cerebral oxygenation after initially successful resuscitation from cardiac arrest (CA). Inadequate oxygenation plausibly aggravates the developing neurological injury [1]. Near-infrared spectroscopy (NIRS) provides a non-invasive technique to assess cerebral oxygenation [2], and the changes in regional cerebral oxygen saturation $\left(\mathrm{rSO}_{2}\right)$ are considered to reflect changes in the relationship between oxygen delivery and consumption in the brain [3]. An increasing body of evidence suggests that optimised cerebral oxygenation is associated with favourable neurologic outcome in a variety of perioperative settings [4]. In addition, higher $\mathrm{rSO}_{2}$ is associated with increased probability of return of spontaneous circulation (ROSC) during cardiopulmonary resuscitation (CPR) [5]. However, the clinical relevance of NIRS during post-resuscitation care remains undefined.

In previous studies including both in-hospital and out-of-hospital cardiac arrest (OHCA) patients, higher $\mathrm{rSO}_{2}$ values during the early post-resuscitation care were associated with better neurological outcome $[6,7]$. On the contrary, in studies including only OHCA patients, the results have been conflicting $[8,9]$. We recently published the results of a randomised pilot trial (Carbon dioxide, Oxygen and Mean arterial Pressure After Cardiac Arrest and REsuscitation (COMACARE)) comparing the effect of different levels of arterial carbon dioxide tension $\left(\mathrm{PaCO}_{2}\right)$, arterial oxygen tension $\left(\mathrm{PaO}_{2}\right)$ and mean arterial pressure (MAP) on surrogate markers of brain injury and on cerebral oxygenation after OHCA. We found that both high-normal $\mathrm{PaCO}_{2}$ and moderate hyperoxia increased $\mathrm{rSO}_{2}$ values but the serum neuron-specific enolase (NSE) concentration was unaffected [10], and the MAP level had no impact on either $\mathrm{rSO}_{2}$ or NSE [11].

In the current study, a post hoc analysis of the COMACARE trial, we assessed the associations between cerebral oxygenation and serum neuron-specific enolase (NSE) concentrations and between cerebral oxygenation and neurological outcome in patients resuscitated from ventricular fibrillation (VF) or ventricular tachycardia (VT).

\section{Methods}

All patients included in this post hoc sub-study were participants of the COMACARE trial (NCT02698917). The COMACARE trial protocol and the main results have been published previously [10-12]. In brief, 123 unconscious, mechanically ventilated patients resuscitated from witnessed OHCA with VF or VT as the initial rhythm were randomly assigned to one of eight arms with each arm having a different combination of targets for $\mathrm{PaCO}_{2}, \mathrm{PaO}_{2}$ and MAP. All patients were treated with targeted temperature management (TTM), and the randomisation was stratified according to the target temperature $\left(33^{\circ} \mathrm{C}\right.$ or $\left.36^{\circ} \mathrm{C}\right)$. The intervention was continued for $36 \mathrm{~h}$ from intensive care unit (ICU) admission or until the patient was extubated or ventilation was set to a spontaneous mode.

The study protocol was approved by the research ethics committees of the Northern Savo Hospital District, Finland (decision No. 295/2015), and the Midtjylland region, Denmark (decision No. 1-10-72-163-16). In addition, the trial protocol was approved by the institutional review board at each site. Because of the nature of the trial, the patients' unconscious state and the need for a timely intervention, obtaining prior informed consent from the participants at the time of randomisation was not possible. Therefore, a deferred consent procedure was approved by the research ethics committee. We randomised the patients and initiated the intervention at the time of ICU admission and obtained deferred informed consent from the patients' next of kin afterwards as soon as possible. In addition, we obtained informed consent from all patients who regained sufficient neurological function for independent decisionmaking [Cerebral Performance Category (CPC) 1-2] after the intervention period.

We measured $\mathrm{rSO}_{2}$ with continuous NIRS during the first $36 \mathrm{~h}$ of intensive care using a Covidien INVOS 5100C device (Covidien Company, USA). Two non-invasive skin sensors, one to each side, were attached to the patient's forehead by a study nurse according to the instructions of the manufacturer. As NIRS monitoring was not part of routine care in the participating ICUs, the treating personnel were blinded from the $\mathrm{rSO}_{2}$ values. Thus, NIRS monitoring results did not affect patient care. We saved the $\mathrm{rSO}_{2}$ values (approximately 10 measurements per minute) from both sensors to a USB memory stick attached to the device. We calculated the hourly medians of these $\mathrm{rSO}_{2}$ values of the left channel and used them in the analyses.

The primary endpoint in this study was serum NSE concentration at $48 \mathrm{~h}$ after CA. We obtained blood samples for the analyses of the NSE concentrations upon ICU admission and $24 \mathrm{~h}, 48 \mathrm{~h}$ and $72 \mathrm{~h}$ after CA. In the Finnish centres, the samples were centrifuged $(2000 \mathrm{~g}, 10 \mathrm{~min})$ and the serum was frozen at $-70^{\circ} \mathrm{C}$ at the hospital laboratory. The measurements of the NSE concentrations were done in ISLAB laboratories (Kuopio, Finland) using a COBAS e601 line (Hitachi High Technology Co, Tokyo, Japan) with an electrochemiluminescent immunoassay kit (Roche Diagnostics $\mathrm{GmbH}$, Mannheim, Germany) in January 2018. Because of possible interference of haemolysis with NSE results, all serum samples were tested for haemolysis using the Roche haemolysis index [13], and all samples with a haemolysis index $\geq 50$ (corresponding to $500 \mathrm{mg}$ of free haemoglobin per litre) $(n=7)$ were excluded from the NSE analyses. At the Aarhus University Hospital, Denmark, the blood samples were analysed immediately by the local 
laboratory using the same kits as those used by the ISLAB laboratory.

The secondary endpoint was neurological outcome assessed with the CPC scale at 6 months after CA. We defined CPC 1-2 as good outcome and CPC 3-5 as poor outcome. One experienced neurologist, blinded to study group allocation, interviewed all patients or their next of kin by telephone and determined the neurologic outcome using the CPC scale.

\section{Statistical methods}

We compared the categorical data between patients with good and poor outcome by using the Chi-square test. We tested the normality of the continuous data with the Kolmogorov-Smirnov test and compared the data with a normal distribution with the Student $t$ test and the data with a non-normal distribution with the Mann-Whitney $U$ test (MWU). We compared the median NSE concentrations at $48 \mathrm{~h}$ after CA between patients with good and poor neurological outcome at 6 months using the MWU. We calculated the median $\mathrm{rSO}_{2}$ during the first $36 \mathrm{~h}$ of intensive care for each patient and then assessed the possible relationship between the median $\mathrm{rSO}_{2}$ and NSE concentrations at 24, 48 and $72 \mathrm{~h}$ using a scatterplot and Spearman's rank-order correlation. We compared the $36-\mathrm{h}$ medians between patients with good and those with poor outcome using the MWU. We compared the $\mathrm{rSO}_{2}$ over time between patients with good and those with poor outcome using a generalised mixed model with a compound-symmetry covariance matrix. We used binary logistic regression model to ascertain the effects of baseline factors and $\mathrm{rSO}_{2}$ on the likelihood of good neurological outcome. We chose to model those factors that were significantly associated with prognosis $(p<0.05)$ in univariate analysis. These factors were age, bystander-initiated resuscitation, delay from collapse to return of spontaneous circulation (ROSC) and Acute Physiology and Chronic Health Evaluation (APACHE) II score (Table 1). Finally, we divided the cohort into tertiles according to the lowest 60-min median $\mathrm{rSO}_{2}$ during the $36-\mathrm{h}$ period and calculated the probability for a good outcome with $95 \%$ confidence interval for each tertile. In addition, we calculated the area under the receiver operating characteristic curve with $95 \%$ confidence interval for the lowest 60-min median $\mathrm{rSO}_{2}$ to predict good outcome in each tertile. We performed all statistical analyses with SPSS version 24.0 (IBM Corporation, USA).

\section{Results}

The flowchart demonstrating patient enrolment is presented in Fig. 1. The patient recruitment began on 22 March 2016 and was completed by 3 November 2017 . The 6-month-follow-up of the last patient was completed by 3 May 2018. The baseline characteristics and resuscitation-associated factors according to the 6-month neurological outcome are presented in Table 1.

The median (inter-quartile range (IQR)) NSE concentration at $48 \mathrm{~h}$ was $17.5(13.4-25.0) \mu \mathrm{g} / \mathrm{l}$ and 35.2 (22.6-95.8) $\mu \mathrm{g} / \mathrm{l}$ in patients with good and poor neurological outcome, respectively, $p<0.001$. We found no statistically significant correlation between median $\mathrm{rSO}_{2}$ during the first $36 \mathrm{~h}$ in the ICU and serum NSE concentration at $48 \mathrm{~h}$ after CA, $r_{s}=-0.08, p=0.392$ (Fig. 2). In addition, there was no correlation between median $\mathrm{rSO}_{2}$ during the first $36 \mathrm{~h}$ in the ICU and serum NSE concentrations at $24 \mathrm{~h}$ or $72 \mathrm{~h}$ after $\mathrm{CA}$ (Additional file 1).

The median (IQR) $\mathrm{rSO}_{2}$ during the first $36 \mathrm{~h}$ of intensive care was $70.0 \%(63.5-77.0 \%)$ in patients with good neurological outcome and $71.8 \%(63.3-74.0 \%)$ in patients with poor neurological outcome, $p=0.943$. There was no significant association between $\mathrm{rSO}_{2}$ over time and neurologic outcome (Fig. 3). In the binary logistic regression model, the median $\mathrm{rSO}_{2}$ during the first $36 \mathrm{~h}$ in the ICU was not a statistically significant predictor of good outcome (adjusted odds ratio 0.99, 95\% confidence interval $0.94-1.04, p=0.635$ ). Additionally, the worst 60-min median $\mathrm{rSO}_{2}$ did not associate with good neurological outcome (Table 2).

\section{Discussion}

We prospectively monitored $\mathrm{rSO}_{2}$ with NIRS monitoring for $36 \mathrm{~h}$ after ICU admission in 118 patients resuscitated from OHCA with VF or VT as initial rhythm. This is, to our knowledge, the largest cohort of post-resuscitation patients with continuous NIRS monitoring during the early intensive care so far, and it is the only cohort including patients exclusively with shockable initial rhythms. We did not find any significant association between $\mathrm{rSO}_{2}$ and NSE concentrations at $48 \mathrm{~h}$ after $\mathrm{CA}$, nor between $\mathrm{rSO}_{2}$ and neurological outcome at 6 months. Our findings question the role of routine NIRS monitoring in these patients.

Pursuing optimal brain oxygenation appears as an intuitively appealing strategy during post-resuscitation care $[14,15]$. Despite its limitations, NIRS provides a non-invasive method to continuously monitor cerebral tissue oxygen saturation in a part of the frontal cortex and to detect clinically silent episodes of cerebral ischaemia [2]. Based on its already widespread use in different perioperative settings and the promising results of $\mathrm{rSO}_{2}$ as a predictor of ROSC during CPR, the expectations have been high that the information provided by NIRS could facilitate optimisation of the treatment of resuscitated patients and provide a feasible target for goal-directed therapy after CA.

The results of previous studies assessing the association between cerebral oxygenation during post-resuscitation care and outcome have been controversial [6-9]. We assessed the possible association between post-resuscitation $\mathrm{rSO}_{2}$ and long-term neurological outcome in a defined population of 
Table 1 Baseline characteristics of the study population according to good (CPC 1-2) or poor (CPC 3-5) 6-month neurological outcome

\begin{tabular}{|c|c|c|c|}
\hline & CPC 1-2 (n=78) & CPC 3-5 $(n=40)$ & $p$-value \\
\hline \multicolumn{4}{|l|}{ Demographic characteristics } \\
\hline Age, mean $\pm \mathrm{SD}$, years & $58 \pm 13$ & $63 \pm 13$ & 0.018 \\
\hline Male sex, $n(\%)$ & $65(83)$ & $31(78)$ & 0.441 \\
\hline Weight, mean $\pm \mathrm{SD}, \mathrm{kg}$ & $84 \pm 16$ & $86 \pm 19$ & 0.932 \\
\hline Neurologic function before cardiac arrest & & & 0.582 \\
\hline Normal, CPC score $1, \mathrm{n}(\%)$ & 72 (92) & $38(95)$ & \\
\hline Some disability, CPC score 2, n (\%) & $6(8)$ & $2(5)$ & \\
\hline \multicolumn{4}{|l|}{ Medical history } \\
\hline Antihypertensive medication, $\mathrm{n}(\%)$ & $36(46)$ & $23(58)$ & 0.243 \\
\hline Chronic heart failure (NYHA class IV), $n$ (\%) a & $0(0)$ & $2(5)$ & 0.046 \\
\hline Inhaled corticosteroids, n (\%) & 1 (3) & $5(8)$ & 0.360 \\
\hline Inhaled bronchodilators, n (\%) & $5(6)$ & $3(8)$ & 0.824 \\
\hline Smoker, $\mathrm{n}(\%)^{\mathrm{b}}$ & $25(32)$ & $15(38)$ & 0.161 \\
\hline Cardiac arrest location & & & 0.038 \\
\hline Home, $\mathrm{n}(\%)$ & $33(42)$ & $25(63)$ & \\
\hline Public place, $\mathrm{n}(\%)$ & $45(58)$ & $15(38)$ & \\
\hline \multicolumn{4}{|l|}{ Resuscitation factors } \\
\hline Bystander-initiated resuscitation, $\mathrm{n}(\%)$ & $68(87)$ & $29(73)$ & 0.048 \\
\hline Time to basic life support, median (IQR), $\min 1$ & $7(6-9)$ & $8(6-10)$ & 0.672 \\
\hline Time to advanced life support, median (IQR), min & $9(7-11)$ & $11(7-13)$ & 0.131 \\
\hline Time to ROSC, median (IQR), min & $17(14-22)$ & $25(21-31)$ & $<0.001$ \\
\hline Intubated during resuscitation, $\mathrm{n}(\%)$ & $31(40)$ & $26(65)$ & 0.009 \\
\hline \multicolumn{4}{|l|}{ Immediate interventional cardiology } \\
\hline Pre-hospital thrombolysis, $\mathrm{n}(\%)$ & $2(3)$ & $2(5)$ & 0.489 \\
\hline Coronary angiography before ICU admission, $\mathrm{n}(\%)$ & $37(48)$ & $24(60)$ & 0.196 \\
\hline \multicolumn{4}{|l|}{ Clinical status on ICU admission } \\
\hline GCS after ROSC, mean $\pm \mathrm{SD}, \min { }^{c}$ & $4 \pm 2$ & $3 \pm 0$ & $<0.001$ \\
\hline APACHE II score, median (IQR) & $27(24-29)$ & $30(26-34)$ & 0.014 \\
\hline Pre-hospital cooling, $\mathrm{n}(\%)$ & $9(12)$ & $1(3)$ & 0.095 \\
\hline Dose of norepinephrine, mean $\pm \mathrm{SD}, \mu \mathrm{g} / \mathrm{kg} / \mathrm{min}$ & $0.07 \pm 0.1$ & $0.06 \pm 0.1$ & 0.712 \\
\hline Time from ROSC to randomisation, median (IQR), min & $173(134-216)$ & $170(141-202)$ & 0.874 \\
\hline Targeted temperature management & & & 0.004 \\
\hline $33^{\circ} \mathrm{C}, \mathrm{n}(\%)$ & $61(78)$ & $21(53)$ & \\
\hline $36^{\circ} \mathrm{C}, \mathrm{n}(\%)$ & $17(22)$ & $19(48)$ & \\
\hline
\end{tabular}

CPC Cerebral Performance Category [1, good cerebral performance (normal life); 2, moderate cerebral disability (disabled but independent); 3, severe cerebral disability (conscious but disabled and dependent); 4, coma or vegetative state (unconscious); 5, brain death]; SD standard deviation, IQR inter-quartile range; NYHA New York Heart Association; CPR cardiopulmonary resuscitation; ICU intensive care unit; GCS Glasgow Coma Scale; ROSC return of spontaneous circulation; APACHE Acute Physiology and Chronic Health Evaluation

a Data missing for 2 patients

${ }^{\mathrm{b}}$ Data missing for 13 patients

'Data missing for 9 patients

${ }^{1}$ The time for a paramedic unit with BLS equipment and skills to reach the patient 


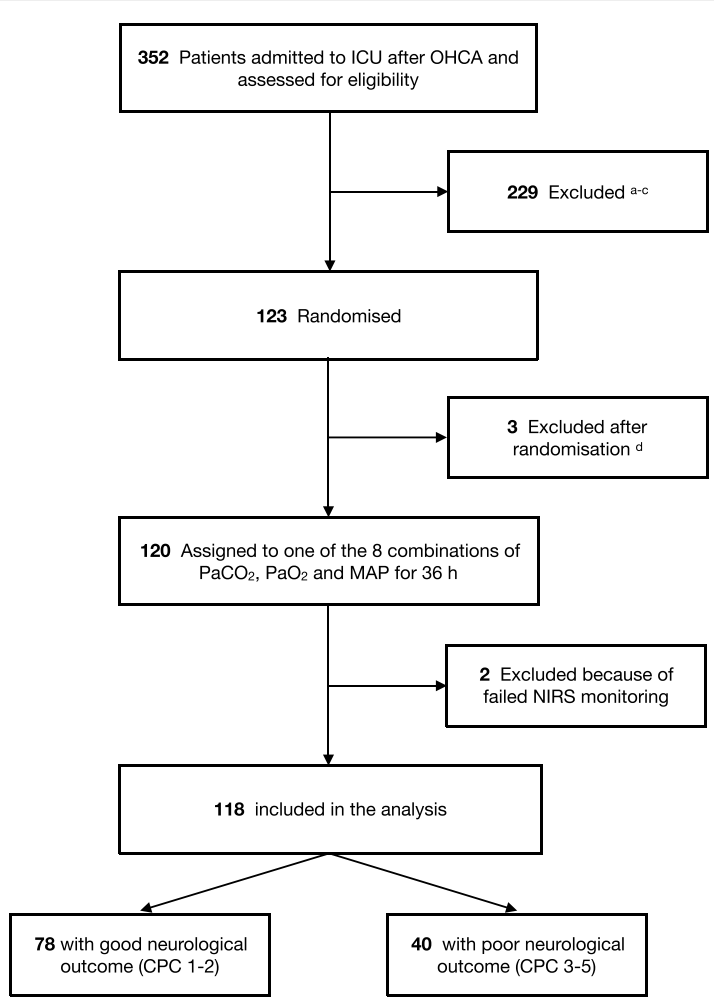

\footnotetext{
a Reasons for not meeting inclusion criteria were as follows: cardiac arrest not witnessed ( $n=82$ ), initial rhythm other than ventricular fibrillation or ventricular tachycardia $(n=104)$, time to return of spontaneous circulation $<10$ or $>$ $45 \mathrm{~min}(n=62)$, cardiac arrest with presumed non cardiac cause (e.g. asphyxia, trauma, massive bleeding, aortic dissection, intracranial bleeding) ( $n=68)$, patient not mechanically ventilated upon ICU admission $(n=7)$, Glasgow Coma Scale motor score 5-6 $(n=45)$, deferred consent from next of kin not possible or likely $(n=17)$ and active intensive care or targeted temperature management not initiated $(n=46)$.

b Exclusion criteria met were as follows: withdrawal from active intensive care due to terminal illness or severely reduced functional status $(n=19)$, confirmed or suspected intracranial pathology and/or suspicion of increased intracranial pressure $(n=15)$, age $<18$ or $>80$ years $(n=26)$, pregnancy $(n=1)$, severe oxygenation disorder at ICU admission $(n=26)$ and severe chronic obstructive pulmonary disease $(n=4)$.

c Other reasons for exclusion were as follows: Iong delay ( $>6 h$ ) from OHCA to ICU admission ( $n=3)$, study personnel was not informed about the patient $(n=3)$, patient died during coronary angiography before ICU admission $(n=1)$, problems with pregnancy test $(n=1)$ and extracorporeal membrane oxygenation initiated at ICU admission $(n=1)$.

d Reasons for exclusion after randomisation were as follows: deferred consent from next of kin denied $(n=2)$, randomisation error $(n=1)$.

Abbreviations: ICU, intensive care unit; $\mathrm{OHCA}$, out-of-hospital cardiac arrest; $\mathrm{PaCO}_{2}$, arterial carbon dioxide tension, $\mathrm{PaO}_{2}$, arterial oxygen tension; MAP, mean arterial pressure; NIRS, near-infrared spectroscopy and CPC, Cerebral
} Performance Category.

Fig. 1 Screened, excluded and included patients in the study

CA patients with shockable initial rhythm and a relatively good prognosis, with $66 \%$ of the patients achieving good neurological outcome. In previous studies that found an association between NIRS values and outcome after CA, the overall rate for good neurological recovery (CPC 1-2) has been $38-47 \%[7,9]$. It is possible that the larger proportion of patients with poor outcome in these cohorts than in our study population may explain the different results.

In the COMACARE trial, high-normal $\mathrm{PaCO}_{2}$ and moderate hyperoxia significantly increased $\mathrm{rSO}_{2}$ values during the first $36 \mathrm{~h}$ of intensive care [10]. However, there was no difference in serum NSE concentrations at 24,48 or $72 \mathrm{~h}$ after CA or neurological outcome at 6 months between any of the intervention groups. This supports the view that achieving higher $\mathrm{rSO}_{2}$ does not necessarily improve chances for good recovery. In many surgical settings, NIRS is used as a perioperative monitor, and changes of $15-20 \%$ from the baseline values are considered meaningful [3]. By contrast, in CA patients, the normal baseline is unknown and the optimal or even minimal level of $\mathrm{rSO}_{2}$ for optimal recovery remains unidentified. In addition, it is possible that the extent of the neuronal damage during CA is the major determinant of outcome and all the secondary changes in cerebral blood flow (CBF) after ROSC have only a minor effect on the patient's prognosis. One may also speculate that increasing oxygen delivery to the brain does not necessarily mean that the damaged neurons are able to utilise oxygen better [16]. 


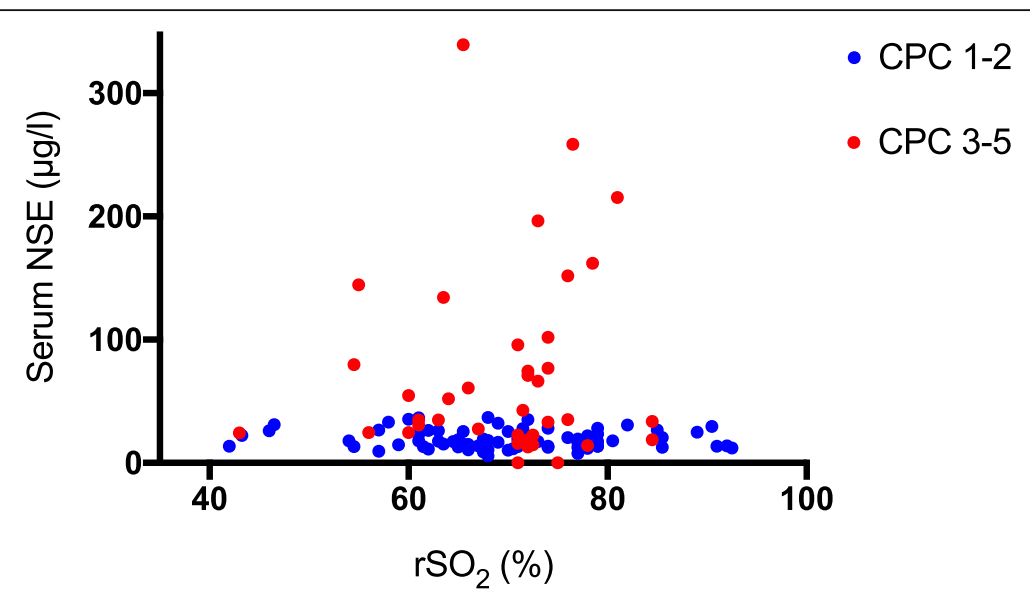

Fig. 2 Scatter plots of serum neuron-specific enolase (NSE) concentration at $48 \mathrm{~h}$ after cardiac arrest vs. median regional cerebral oxygen saturation $\left(\mathrm{rSO}_{2}\right)$ during the first $36 \mathrm{~h}$ in intensive care unit in patients with good (Cerebral Performance Category [CPC] 1-2) and poor (CPC 3-5) neurological outcome

$\mathrm{RSO}_{2}$ is thought to reflect CBF, and a recent study found a moderate correlation between $\mathrm{rSO}_{2}$ and cerebral perfusion pressure (CPP) [17]. However, the significance of optimising $\mathrm{CPP}$ and $\mathrm{CBF}$ to improve outcomes during post-resuscitation care remains undefined. In another study assessing $\mathrm{CBF}$ with serial duplex ultrasound measurements after $\mathrm{CA}$, there was no association between CBF and outcome [18], which is in accordance with our finding of the lack of correlation between $\mathrm{rSO}_{2}$ and outcome. Interestingly, a correlation was found between the systemic blood pressure and CBF in patients with poor outcome, suggesting that impaired autoregulation of CBF during post-resuscitation care is related to poor prognosis. Impaired autoregulation during the first $24 \mathrm{~h}$ after CA has indeed been previously associated with poor outcome [19]. It is possible that $\mathrm{rSO}_{2}$ monitoring might be useful in the assessment of autoregulation, but more research is needed to determine its role.

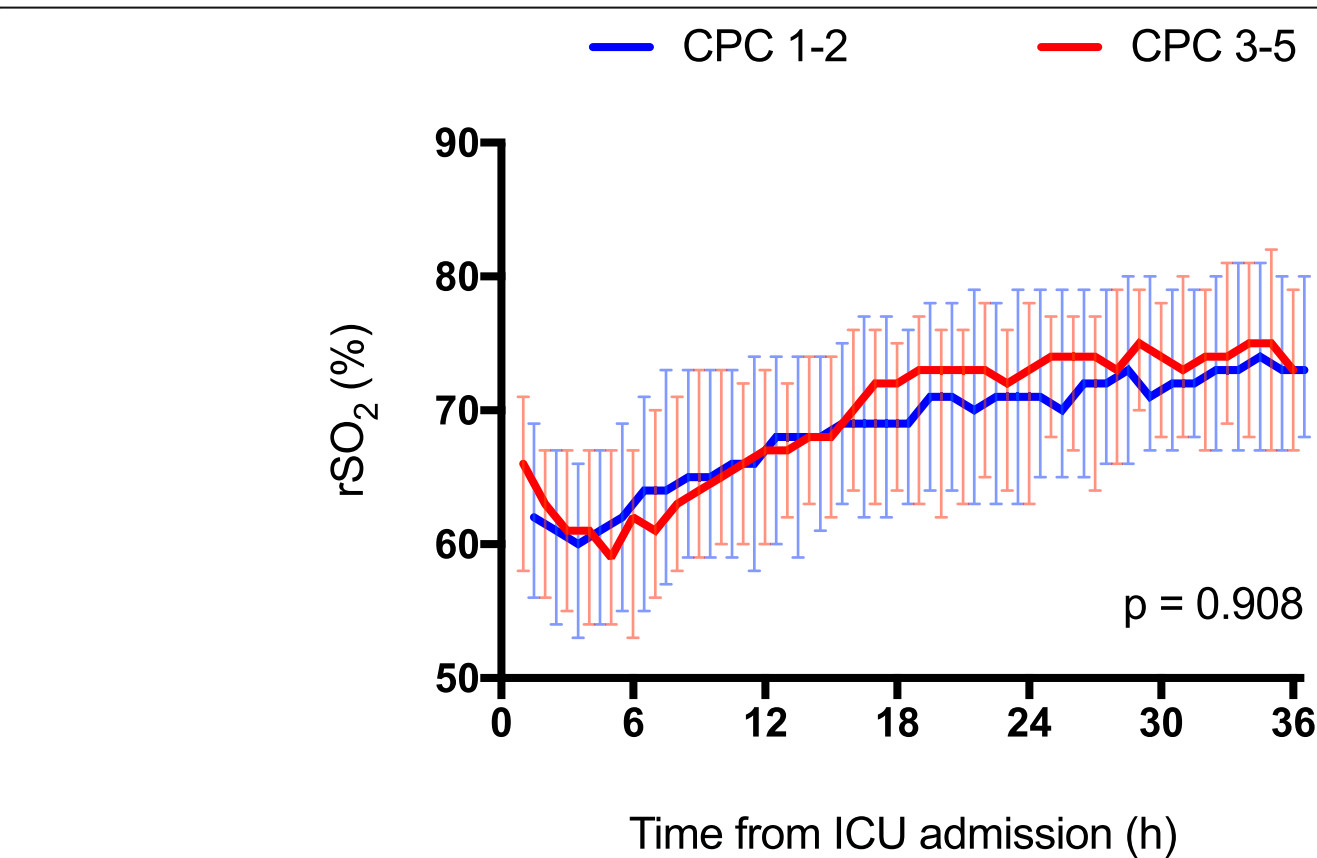

Fig. 3 Median (inter-quartile range) regional cerebral oxygen saturation $\left(\mathrm{rSO}_{2}\right)$ during the first $36 \mathrm{~h}$ of intensive care in patients with good (Cerebral Performance Category [CPC] 1-2) and poor (CPC 3-5) neurological outcome 
Table 2 The probability for a good outcome (CPC 1-2) and the area under the receiver operating characteristic curve for the lowest 60 -min median $\mathrm{rSO}_{2}$ to predict good outcome overall and in tertiles based on the lowest 60-min median $\mathrm{rSO}_{2}$ during the first $36 \mathrm{~h}$ in ICU

\begin{tabular}{|c|c|c|c|c|c|}
\hline \multirow[b]{2}{*}{ All patients } & & \multicolumn{2}{|c|}{ CPC 1-2, \% (95\% Cl) } & \multicolumn{2}{|c|}{ AUC $(95 \% \mathrm{Cl})$} \\
\hline & & 66.1 & $(57.3-74.2)$ & 0.524 & $(0.416-0.631)$ \\
\hline \multirow{3}{*}{$\begin{array}{l}\text { Tertile group } \\
\text { according to the } \\
\text { lowest } 60 \text { min } \\
\text { median } \mathrm{rSO}_{2}\end{array}$} & 1 & 68.3 & $(53.2-80.9)$ & 0.544 & $(0.353-0.735)$ \\
\hline & 2 & 60.0 & $(44.6-74.1)$ & 0.520 & $(0.337-0.702)$ \\
\hline & 3 & 70.3 & (54.4-83.1) & 0.594 & $(0.389-0.800)$ \\
\hline
\end{tabular}

Abbreviations: CPC, Cerebral Performance Category; $\mathrm{rSO}_{2}$, regional cerebral oxygen saturation; ICU, intensive care unit; $\mathrm{Cl}$, confidence interval; $\mathrm{AUC}$, area under the curve.

$C P C$ cerebral performance category, $r S O 2$ regional cerebral oxygen saturation, $I C U$ intensive care unit, $C /$ confidence interval, $A U C$ area under the curve

The current study has several strengths. First, this was a large cohort of resuscitated patients with continuous NIRS monitoring. Second, we assessed the association of cerebral oxygenation with outcome in patients resuscitated from exclusively shockable initial rhythms. Third, we used continuous NIRS monitoring applied soon after ICU admission and continued for $48 \mathrm{~h}$. Fourth, the physicians and ICU personnel responsible for the intensive care of the study patients were blinded to the NIRS monitor readings. Fifth, we treated all patients according to the current guidelines for postresuscitation intensive care including targeted temperature management at either $33^{\circ} \mathrm{C}$ or $36^{\circ} \mathrm{C}$. Finally, we studied patients in multiple centres and in two different countries.

Our study has some limitations. First, the design of this sub-study was conceived post hoc and was not included in the original COMACARE protocol [12]. Second, we did not assess CBF by transcranial Doppler ultrasound. $\mathrm{As}_{\mathrm{rSO}}$ is a surrogate indicator of $\mathrm{CBF}$, transcranial Doppler could have provided additional information. Third, we used NIRS probes attached on the patients' forehead which provides information about a small area of the frontal cerebral cortex, leaving other parts of the brain uncovered. Thus, we cannot exclude regional variation in $\mathrm{rSO}_{2}$ which could have caused bias to our results. Fourth, the fact that we studied a relatively selected population of CA patients with only shockable initial rhythms limits the generalisability of the results. Finally, although we studied patients in multiple centres, a majority were recruited in one hospital.

\section{Conclusions}

We did not find any association between cerebral oximetry $\left(\mathrm{rSO}_{2}\right)$ during the first $36 \mathrm{~h}$ of post-resuscitation intensive care and NSE serum concentrations at $48 \mathrm{~h}$ after OHCA or neurological outcome at 6 months.

\section{Additional file}

Additional file 1: Association between $\mathrm{rSO}_{2}$ and the NSE concentrations at $24 \mathrm{~h}$ and $72 \mathrm{~h}$. The scatterplots and the results of the Spearman rank order correlation analyses concerning the associations between $\mathrm{rSO}_{2}$ and the serum NSE concentrations at $24 \mathrm{~h}$ and $72 \mathrm{~h}$ after cardiac arrest. (PDF $171 \mathrm{~kb}$ )

\section{Abbreviations}

APACHE: Acute Physiology and Chronic Health Evaluation; CA: Cardiac arrest; CBF: Cerebral blood flow; CPC: Cerebral performance category; CPP: Cerebral perfusion pressure; CPR: Cardiopulmonary resuscitation; ICU: Intensive care unit; IQR: Inter-quartile range; MAP: Mean arterial pressure; MWU: Mann-Whitney $U$ test; NIRS: Near-infrared spectroscopy; NSE: Neuron-specific enolase; OHCA: Out-of-hospital cardiac arrest; $\mathrm{PaCO}_{2}$ : Arterial carbon dioxide tension; $\mathrm{PaO}_{2}$ : Arterial oxygen tension; ROSC: Return of spontaneous circulation; $\mathrm{rSO}_{2}$ : Regional cerebral oxygen saturation; TTM: Targeted temperature management; VF: Ventricular fibrillation; VT: Ventricular tachycardia

\section{Acknowledgements}

COMACARE study group

Aarhus University Hospital: Thomas Birkelund, Susanne Ilkjaer, and Hans Kirkegaard; Central Finland Central Hospital: Raili Laru-Sompa, Anni Pulkkinen, Mikko Reilama, and Sinikka Tolmunen; Helsinki University Hospital: Minna Bäcklund, Jonna Heinonen, Johanna Hästbacka, Pekka Jakkula, Nina Lundbom, Marcus Norrgård, Marjatta Okkonen, Ville Pettilä, Markus B Skrifvars, Tarja Suhonen, Marjaana Tiainen, Tuukka Tikka, Marjut Timonen, Jussi Toppila, Miia Valkonen, and Erika Wilkman; Jorvi Hospital: Teemu Hult and Tuomas Oksanen; Kuopio University Hospital: Stepani Bendel, Elina Halonen, Sari Rahikainen, Saija Rissanen, and Eija Vaskelainen; North Karelia Central Hospital: Tanja Eiserbeck, Sirkku Heino, Helena Jyrkönen, Matti Reinikainen, Johanna Räsänen, and Tero Surakka; Päijät-Häme Central Hospital: Talvikki Koskue, Petteri Kujala, Pekka Loisa, and Marika Lähde; Tampere University Hospital: Jari Kalliomäki, Sari Karlsson, Atte Kukkurainen, and Simo Varila.

\section{Funding}

Independent funding support has been received from Helsinki University; Helsinki University Hospital (State funding, Finland); Stiftelsen Dorothea Olivia, Karl Walter och Jarl Walter Perkléns minne; The Laerdal Foundation for Acute Medicine; Medicinska Understödsföreningen Liv och Hälsa; Finska Läkaresällskapet; The Finnish Society of Anaesthesiologists; Orion Research Foundation and Svenska kulturfonden. The funding bodies had no input regarding the design, management, or reporting of the trial. 


\section{Availability of data and materials}

The data that support the findings of this study are available on request from the corresponding author. The data are not publicly available because they contain information that could compromise research participant privacy.

\section{Authors' contributions}

PJ designed the study, actively recruited patients, analysed the results and was responsible for preparing the manuscript. JH, MR and VP designed the study, actively recruited patients and were major contributors to the writing of the manuscript. MT contributed to the study design, was responsible for the assessment of neurological outcome at 6 months and reviewed the manuscript. MS designed the study, obtained funding, actively recruited patients and was a major contributor to the writing of the manuscript. All other authors actively recruited patients for the study and reviewed and approved the final manuscript.

\section{Ethics approval and consent to participate}

The study protocol was approved by the research ethics committees of the Northern Savo Hospital District, Finland (decision No. 295/2015), and the Midtjylland region, Denmark (decision No. 1-10-72-163-16). In addition, the trial protocol was approved by the institutional review board at each site. A deferred consent to participate was obtained from the patients' next of kin. In addition, an informed consent was obtained from all patients who regained sufficient neurological function for independent decision-making (CPC 1-2) after the intervention period.

\section{Consent for publication}

Not applicable.

\section{Competing interests}

The authors declare that they have no competing interests.

\section{Publisher's Note}

Springer Nature remains neutral with regard to jurisdictional claims in published maps and institutional affiliations.

\section{Author details}

'Department of Anaesthesiology, Intensive Care and Pain Medicine, University of Helsinki and Helsinki University Hospital, Helsinki, Finland. ${ }^{2}$ Department of Anaesthesiology and Intensive Care, University of Eastern Finland and Kuopio University Hospital, Kuopio, Finland. ${ }^{3}$ Department of Intensive Care, Päijät-Häme Central Hospital, Lahti, Finland. ${ }^{4}$ Department of Neurology, University of Helsinki and Helsinki University Hospital, Helsinki, Finland. ${ }^{5}$ Department of Intensive Care, Kuopio University Hospital, Kuopio, Finland. ${ }^{6}$ Aarhus University Hospital, Aarhus, Denmark. ${ }^{7}$ Department of Intensive Care, Central Finland Central Hospital, Jyväskylä, Finland. ${ }^{8}$ Department of Anaesthesiology and Intensive Care, North Karelia Central Hospital, Joensuu, Finland. ${ }^{9}$ Department of Intensive Care, Tampere University Hospital, Tampere, Finland. ${ }^{10}$ Department of Emergency Medicine and Services, University of Helsinki and Helsinki University Hospital, Helsinki, Finland.

Received: 19 February 2019 Accepted: 9 April 2019

Published online: 14 May 2019

\section{References}

1. Buunk G, van der Hoeven JG, Meinders AE. Cerebrovascular reactivity in comatose patients resuscitated from a cardiac arrest. Stroke. 1997;28:1569-73.

2. Murkin JM, Arango M. Near-infrared spectroscopy as an index of brain and tissue oxygenation. Br J Anaesth. 2009;103:i3-i13.

3. Green DW, Kunst G. Cerebral oximetry and its role in adult cardiac, non-cardiac surgery and resuscitation from cardiac arrest. Anaesthesia. 2017;72:48-57.

4. Moerman A, De Hert S. Cerebral oximetry. Curr Opin Anaesthesiol. 2015;28:703-9.

5. Schnaubelt S, Sulzgruber P, Menger J, Skhirtladze-Dworschak K, Sterz F, Dworschak M. Regional cerebral oxygen saturation during cardiopulmonary resuscitation as a predictor of return of spontaneous circulation and favourable neurological outcome - a review of the current literature. Resuscitation. 2018;125:39-47.
6. Ahn A, Yang J, Inigo-Santiago L, Parnia S. A feasibility study of cerebral oximetry monitoring during the post-resuscitation period in comatose patients following cardiac arrest. Resuscitation. 2014;85:522-6.

7. Storm C, Leithner C, Krannich A, Wutzler A, Ploner CJ, Trenkmann L, et al. Regional cerebral oxygen saturation after cardiac arrest in 60 patients-a prospective outcome study. Resuscitation. 2014;85:1037-41.

8. Bouglé A, Daviaud F, Bougouin W, Rodrigues A, Geri G, Morichau-Beauchant T, et al. Determinants and significance of cerebral oximetry after cardiac arrest: a prospective cohort study. Resuscitation. 2016;99:1-6.

9. Genbrugge C, Eertmans W, Meex I, Van Kerrebroeck M, Daems N, Creemers $A$, et al. What is the value of regional cerebral saturation in post-cardiac arrest patients? A prospective observational study. Crit Care. 2016;20:1-9.

10. Jakkula P, Reinikainen M, Hästbacka J, Loisa P, Tiainen M, Pettilä V, et al. Targeting two different levels of both arterial carbon dioxide and arterial oxygen after cardiac arrest and resuscitation: a randomised pilot trial. Intensive Care Med. 2018;44:2112-21.

11. Jakkula $P$, Pettilä V, Skrifvars MB, Hästbacka J, Loisa $P$, Tiainen $M$, et al. Targeting low-normal or high-normal mean arterial pressure after cardiac arrest and resuscitation: a randomised pilot trial. Intensive Care Med. 2018:44:2091-101.

12. Jakkula P, Reinikainen M, Hästbacka J, Pettilä V, Loisa P, Karlsson S, et al. Targeting low- or high-normal Carbon dioxide, Oxygen, and Mean arterial pressure After Cardiac Arrest and REsuscitation: study protocol for a randomized pilot trial. Trials. 2017;18:1-9.

13. Petrova DT, Cocisiu GA, Eberle C, Rhode K-H, Brandhorst G, Walson PD, et al. Can the Roche hemolysis index be used for automated determination of cell-free hemoglobin? A comparison to photometric assays. Clin Biochem. 2013;46:1298-301.

14. Llitjos J-F, Mira J-P, Duranteau J, Cariou A. Hyperoxia toxicity after cardiac arrest: what is the evidence? Ann Intensive Care. 2016;6:1-9.

15. Buunk G, van der Hoeven JG, Meinders AE. Prognostic significance of the difference between mixed venous and jugular bulb oxygen saturation in comatose patients resuscitated from a cardiac arrest. Resuscitation. 1999;41:257-62.

16. Fink M. Cytopathic hypoxia in sepsis. Acta Anaesthesiol Scand. 1997;1 10:87-95.

17. Taccone FS, Crippa IA, Creteur J, Rasulo F. Estimated cerebral perfusion pressure among post-cardiac arrest survivors. Intensive Care Med. 2018;44:966-7.

18. Connolly FD, Reitemeier J, Storm C, Hasper D, Schreiber SJ. Duplex sonography of cerebral blood flow after cardiac arrest-a prospective observational study. Resuscitation. 2014;85:516-21.

19. Ameloot K, Genbrugge C, Meex I, Jans F, Boer W, Vander Laenen M, et al. An observational near-infrared spectroscopy study on cerebral autoregulation in post-cardiac arrest patients: time to drop "one-size-fits-all" hemodynamic targets? Resuscitation. 2015;90:121-6.

\section{Ready to submit your research? Choose BMC and benefit from:}

- fast, convenient online submission

- thorough peer review by experienced researchers in your field

- rapid publication on acceptance

- support for research data, including large and complex data types

- gold Open Access which fosters wider collaboration and increased citations

- maximum visibility for your research: over $100 \mathrm{M}$ website views per year

At BMC, research is always in progress.

Learn more biomedcentral.com/submissions 